\title{
Avaliação Espermática Pós-Descongelamento em Piracanjuba (Brycon orbignyanus, Vallenciennes, 1849)
}

\author{
Luis David Solis Murgas', Renan Toledo Franciscatto², Anna Graciela Oliveira Santos ${ }^{3}$
}

\begin{abstract}
RESUMO - O experimento foi realizado com o objetivo de testar o efeito de dois meios diluidores (Glicose 5\% e água de côco) no congelamento do sêmen de piracanjuba (Brycon orbignyanus, Vallenciennes, 1849$)$ e dois descongelamentos do sêmen $\left(60^{\circ} \mathrm{C}\right.$ durante 5 segundos e $50^{\circ} \mathrm{C}$ durante 10 segundos). Foi utilizado como ativador da motilidade espermática pós-descongelamento o bicarbonato de sódio $1 \%$. Um fatorial 2 x 2 foi utilizado para analisar o efeito dos dois modelos de descongelamento e dos diluidores sobre a motilidade espermática pós-descongelamento, sua duração e porcentagem de espermatozóides vivos pós-descongelamento. A motilidade espermática pós-descongelamento média foi de $74,17 \pm 22,45 \%$, quando se utilizou a glicose $5 \%$ como diluidor e descongelamento a $50^{\circ} \mathrm{C}$, durante 10 segundos, observando-se diferença significativa na interação entre diluidor e descongelamento. A duração da motilidade espermática não apresentou diferença entre os diluidores e descongelamentos, com média de 153,33 $\pm 59,61$ segundos. A porcentagem de espermatozóides vivos pode ser utilizada para avaliação de sêmen de peixes e apresentou resultados significativos apenas quando da interação entre descongelamento a $50^{\circ} \mathrm{C}$ durante 10 segundos e diluidor com glicose $5 \%$. Esta combinação foi mais efetiva na preservação da integridade dos espermatozóides de piracanjuba pós-descongelamento, com média de 67,83 \17,67\% de espermatozóides vivos.
\end{abstract}

Palavras-chave: Brycon orbignyanus, criopreservação, sêmen

\section{Sperm Evaluation of Piracanjuba Fish (Brycon orbignyanus, Vallenciennes, 1849), after Thawing}

ABSTRACT - The aim of this experiment was to test the effects of two extenders (Glucose 5\% and Coconut Water) and two thawing rates $\left(60^{\circ} \mathrm{C}\right.$ during 5 seconds and $50^{\circ} \mathrm{C}$ during 10 seconds) for semen of Piracanjuba (Brycon orbygnianus, Vallencienens, 1849). A solution of $\mathrm{NaHCO}_{3} 1 \%$ was used to activate motility. A factorial $2 \times 2$ was used to analyze the results on sperm motility and its duration, and the percentage of living sperm after thawing. The highest sperm motility values $(74.17 \pm 22.45 \%)$ were achieved when the combination of coconut water and thawing rates of $50^{\circ} \mathrm{C}$ during 10 seconds was used. The other combinations of extender and thawing rates produced lower sperm motility. The sperm motility duration was not affected by any of the combinations of extenders and thawing rates. The thawing rates showes the average of $153.33 \pm 59.61$ seconds. The highest percentage of living sperm values $(67.83 \pm 17.67 \%)$ was obtained when the combination of glucose $5 \%$ and thawing rates of $50^{\circ} \mathrm{C}$ during 10 seconds was used. This combination was more effective on the preservation of sperm piracanjuba integrity after freezing.

Key Words: Brycon orbygnianus, criopreservation, semen

\section{Introdução}

A piracanjuba (Brycon orbignyanus Valenciennes, 1849) é reofílica e encontra-se distribuída na bacia do Paraná-Uruguai, principalmente nos Rios Grande e Paraná (Castagnolli, 1992).

Este gênero despertou grande interesse pelas instituições de pesquisa nos últimos anos, tanto pela excelente qualidade da carne, quanto pelo hábito alimentar no ambiente natural, preferencialmente composto por frutos e sementes. Além disso, o rápido crescimento e o ganho de peso demonstrados em criações experimentais são indicadores para a sele- ção dessa espécie como alternativa para o desenvolvimento da piscicultura nas regiões Norte, CentroOeste, Sudeste, Nordeste e Sul do Brasil, segundo Vasques (1997).

Segundo Castagnolli (1992), os briconídeos são peixes de piracema (reofílicos) muito dependentes de alimentos alóctones (frutos e sementes). Portanto, foram muito prejudicados pela construção de barragens nos rios e desmatamento da vegetação ciliar. Além disso, as grandes barragens constituem barreira intransponível, na rota migratória dos peixes de piracema, que são os mais valiosos do ponto de vista da pesca, reduzindo ou eliminando sua eficiência

\footnotetext{
1 Médico Veterinário, Dr., Professor adjunto do Departamento de Medicina Veterinária da UFLA, Lavras - MG - CEP: $37200-000$, Brasil. E.mail: Ismurgas@ufla.br

2 Acadêmico do curso de Medicina Veterinária da UFLA e Bolsista do CNPq. E.mail: renan@ufla.br

3 Acadêmica do curso de Medicina Veterinária da UNIFENAS.
} 
reprodutiva segundo Bedore et al. (1999). Essa interrupção no ciclo natural da espécie interfere diretamente no processo reprodutivo, podendo assim levar a extinção das espécies nativas da região (Silva et al., 1995).

Além de existir grande interesse na utilização deste briconídeo para o repovoamento de reservatórios hidrelétricos e pisciculturas comerciais, o desenvolvimento da piscicultura com espécies nativas é de grande interesse para a conservação da biodiversidade e se constitui prioridade do IBAMA, de acordo com Conte (1995).

Santos (1981) relata que a carne de piracanjuba apresenta, além de convidativo aspecto, finíssimo sabor, podendo rivalizar com os mais saborosos pescados dos rios europeus. É uma espécie arisca, mas muito apreciada na pesca esportiva, motivo pelo qual tem sido muito procurada para o povoamento de tanques em pesque-pagues.

Devido a sua heterogeneidade, o espermatozóide de peixe ocupa uma posição importante na história da criobiologia. A diversidade evolucionária e grandes diferenças na nutrição e natureza resultaram em consideráveis diferenças entre as propriedades fisiológicas, bioquímicas e morfológicas dos gametas de peixes. Com isso, tornam-se necessários estudos visando o desenvolvimento de métodos eficientes de criopreservação para as diferentes espécies (Drokin \& Bartscherer, 1998).

De forma geral, os espermatozóides dos peixes são imóveis nos testículos, iniciando sua motilidade em contato com a água. No caso de espécies de água doce, a motilidade espermática resulta, principalmente, da drástica redução da pressão osmótica do meio e pela diluição das altas concentrações de potássio $\left(\mathrm{K}^{+}\right)$do plasma seminal (BGIP, 1990; Stoss \& Donaldson, 1982; Mutr \& Roberts, 1993).

Uma vez que os espermatozóides iniciam o movimento, perdem rapidamente sua reserva de energia. Épossível mantê-los imóveis, quando a pressão osmótica do meio é suficientemente alta (BGIP, 1990).

Diante da ausência de trabalhos visando à criopreservação do sêmen de piracanjuba, objetivou-se estudar o processo, bem como verificar a viabilidade póscongelamento dos espermatozóides da referida espécie.

\section{Material e Métodos}

Este trabalho foi conduzido na Estação Experimental da Usina Hidrelétrica da Companhia Energética do Estado de Minas Gerais (CEMIG), em ItutingaMG e no Laboratório de Fisiologia e Farmacologia da
Universidade Federal de Lavras (UFLA), em Lavras-MG. O processo de coleta e o congelamento do sêmen foram realizados durante o período de reprodução 1998-1999. O descongelamento do sêmen, bem como as análises de suas características póscongelamento, foi realizado em agosto de 2001.

Foram utilizados nove reprodutores de piracanjuba (B. orbignyanus) com peso corporal médio de $566,7 \mathrm{~g}$. O critério de seleção dos exemplares baseou-se na liberação de esperma após leve pressão abdominal no sentido ântero-posterior.

Os peixes selecionados foram submetidos a hipofisação, recebendo três injeções intramusculares de extrato de hipófise de carpa (EHC). A primeira dose, chamada "prévia", foi de 0,25 mg de EHC/kg. Após intervalo de 8 horas, administrou-se uma segunda dose de $0,4 \mathrm{mg}$ de $\mathrm{EHC} / \mathrm{kg}$, chamada de primeira "aplicação efetiva", e 12 horas depois realizou-se uma segunda "aplicação efetiva" de 4,0 mg de EHC/kg .

O sêmen foi extraído, individualmente, de cada reprodutor através de massagem abdominal ânteroposterior e coletado separadamente em tubos de ensaio graduados, os quais foram colocados em água a temperatura de $28^{\circ} \mathrm{C}$ e protegido da luz.

Para o congelamento do sêmen foram utilizados dois diluidores:

1. Diluidor 1(D1)-Glicose 5\%, dimetil sulfóxido $10 \%$ e gema de ovo $5 \%$, em água destilada;

2. Diluidor 2(D2) - Dimetil sulfóxido 10\% e gema de ovo $5 \%$, em água de côco.

Logo após a diluição, os parâmetros de motilidade espermática e duração da motilidade foram avaliados com auxílio de microscopia óptica utilizando aumento de $400 \mathrm{X}$.

O sêmen então foi acondicionado em palhetes de plásticos de $0,5 \mathrm{~mL}$ e colocado em contato com vapor de nitrogênio líquido em recipiente criogênico "termo seco" canadense. Posteriormente, os palhetes foram transferidos para botijões criogênicos convencionais e submersos no nitrogênio líquido, onde ficaram armazenados durante 33 meses aproximadamente.

Para o processo de descongelamento, foram utilizadas duas temperaturas, com tempos diferentes. Um grupo de palhetes foi descongelado em banhomaria à temperatura de $60^{\circ} \mathrm{C}$ por 5 segundos e outro grupo, descongelado em banho-maria à temperatura de $50^{\circ} \mathrm{C}$ por 10 segundos.

Foi utilizado como ativador de motilidade espermática pós-congelamento bicarbonato de sódio $1 \%$ (Murgas et al, 1998). Em seguida, foi analisado o material seminal 
submetido a D1 e D2 com cada um dos diferentes tipos de descongelamento, em microscópio óptico (400 e 1000x). Os parâmetros analisados foram a porcentagem de motilidade, a duração da motilidade (segundos) e porcentagem de espermatozóides vivos.

A avaliação da motilidade e sua duração foram realizadas em lâmina com uma gota de sêmen e uma gota do ativador de motilidade espermática (bicarbonato de Sódio 1\%), levada ao microscópio e observada em aumento de 400X. A valorização da motilidade dos espermatozóides baseou-se na estimativa da porcentagem de células móveis no campo focalizado, segundo a escala arbitrária de 0 a 100\% (Silva et al. 1998). A duração da motilidade espermática foi medida com o auxílio de um cronômetro comum, até baixar a $10 \%$ de células móveis.

Para avaliação da integridade de membrana, foi usado o corante eosina-nigrosina.

Após descongelamento e ativação dos espermatozóides com bicarbonato de sódio a $1 \%$, foi elaborado um esfregaço em uma lâmina, na qual foram colocadas uma gota de sêmen e uma de corante, seco ao ar e levado ao microscópio óptico (1000x). Foram identificadas 100 células para verificação de espermatozóides vivos que não se coram e os mortos que absorveram o corante, tornando-se de coloração avermelhada.

Utilizou-se um delineamento inteiramente ao acaso com seis repetições e os tratamentos dispostos em uma estrutura fatorial $2 \times 2$.

O modelo estatístico do experimento foi o seguinte:

$$
\mathrm{Y}_{\mathrm{ijk}}=\mathrm{m}+\mathrm{a}_{\mathrm{i}}+\mathrm{b}_{\mathrm{j}}+(\mathrm{ab})_{\mathrm{ij}}+\mathrm{e}_{\mathrm{ijk}}
$$

em que $Y_{\mathrm{ijk}}=$ característica avaliada, referente ao diluidor i e descongelamento $\mathrm{j}$, na repetição $\mathrm{k}$; $\mathrm{m}=$ média geral; $\mathrm{a}_{\mathrm{i}}=$ efeito do diluidor $\mathrm{i}$, sendo $\mathrm{i}=$ $1 \mathrm{e} 2 ; \mathrm{b}_{\mathrm{j}}=$ efeito do descongelamento $\mathrm{j}$, sendo $\mathrm{j}=1$ e 2; $(\mathrm{ab})_{\mathrm{ij}}=$ efeito da interação entre o diluidor i e o descongelamento $\mathrm{j} ; \mathrm{e}_{\mathrm{ijk}}=$ erro aleatório associado a cada observação, considerado normal e independemente distribuído com média 0 e variância $\sigma^{2}$.

Os resultados obtidos foram submetidos à análise estatística através do pacote computacional Sisteme de Análise de Variâncias SISVAR (Ferreira, 1999), sendo as médias comparadas pelo teste Tukey.

\section{Resultados e Discussão}

A análise de variância para os parâmetros avaliados (motilidade, duração da motilidade e percentagem de espermatozóides vivos) mostrou que não houve diferença significativa $(\mathrm{P}>0,05)$ entre as duas temperaturas de descongelamento e entre os diluidores utilizados. Entre a motilidade espermática e porcentagem de espermatozóides vivos sua interação apresentou significância $(\mathrm{P}<0,05)$.

$\mathrm{O}$ valor médio observado para a motilidade no sêmen in natura pré-congelamento foi de $97,77 \%$. Após diluição do sêmen com o diluidor com glicose $5 \%$, o resultado para motilidade média foi de $73,33 \%$ e para o sêmen com o diluidor com água de côco foi de $75,55 \%$. Os resultados aqui constatados são semelhantes aos mostrados por Franciscatto et al (2001), que, trabalhando com a piapara (Leporinus obtisidens), obtiveram $88,21 \%$ de motilidade média no sêmen in natura. Os resultados da motilidade espermática observada após o descongelamento do sêmen usando como diluidores glicose $5 \%$ (D1) e a água de côco (D2), com os diferentes tipos de descongelamento, estão apresentados na Tabela 1.

Houve diferença significativa $(\mathrm{P}>0,05)$ para a motilidade espermática, observada no descongelamento a $50^{\circ} \mathrm{C}$ durante 10 segundos, utilizando os diferentes diluidores mostrando D1 (glicose 5\%) com melhor resultado que D2 (água de côco). Diferentemente, no descongelamento a $60^{\circ} \mathrm{C}$ durante 5 segundos, o diluidor D2 e D1 apresentaram resultados semelhantes $(\mathrm{P}>0,05)$. Esses resultados são superiores aos observados por Silva et al (1998), que trabalhando com a espécie pacu (Piractus mesopotamicus), encontraram taxas de motilidade de 30 e $53 \%$ para sêmen dessa espécie após o descongelamento. Mello et al. (1998), também trabalhando com pacu, obtiveram resultados de motilidade após descongelamento de $10 \%$ em sêmen com glicose e de 5\% de sêmen com água de côco in natura e com LMN (diluidor à base de EDTA), obtendo resultados de valor inferior aos desse experimento, principalmente com relação ao diluidor água de côco. Os resultados médios da duração da motilidade espermática observada pré-congelamento foram de 182,66 segundos para sêmen in natura, 46,44 segundos para sêmen diluído com D1 e de 47,88 segundos para sêmen diluído com D2. Os resultados médios alcançados por Franciscatto et al. (2001), para duração da motilidade, foram de 121,79 segundos, próximos aos encontrados nesse experimento, que, após o descongelamento do sêmen usando como diluidores a glicose 5\% (D1) e a água de côco (D2) em temperatura de $50^{\circ} \mathrm{C}$ durante 10 segundos e a $60^{\circ} \mathrm{C}$ durante 5 segundos, mostrou resultados de duração da motilidade

R. Bras. Zootec., v.32, n.6, p.1810-1814, 2003 (Supl. 2) 
Tabela 1 - Motilidade espermática observada no sêmen de piracanjuba pós-descongelamento

Table 1 - Sperm motility of piracanjuba semen after thawing

\begin{tabular}{lcc}
\hline \multirow{2}{*}{$\begin{array}{l}\text { Descongelamentos } \\
\text { Thawing rates }\end{array}$} & \multicolumn{2}{c}{$\begin{array}{c}\text { Motilidade espermática (\%) } \\
\text { Sperm motility }(\%)\end{array}$} \\
\cline { 2 - 3 } & $\begin{array}{l}\text { Glicose 5\%(D1) } \\
\text { Glucose 5\% (D1) }\end{array}$ & $\begin{array}{c}\text { Água de côco (D2) } \\
\text { Coconut water (D2) }\end{array}$ \\
\hline $50^{\circ} \mathrm{C} / 10 \mathrm{~s}$ & $74,17 \pm 22,45 \mathrm{a}$ & $56,67 \pm 13,66 \mathrm{a}$ \\
$60^{\circ} \mathrm{C} / 5 \mathrm{~s}$ & $51,67 \pm 14,72 \mathrm{~b}$ & $66,67 \pm 18,62 \mathrm{a}$ \\
\hline
\end{tabular}

Médias seguidas da mesma letra na mesma coluna não apresentam diferenças significativas pelo teste Tukey, em nível de $5 \%$. Means in the same column with the same following letters show no significant differences by Tukey test at $5 \%$ probability level.

espermática, apresentados na Tabela 2.

Os valores encontrados por Silva et al. (1998), para duração da motilidade de sêmen de curimba (Prochilodus lineatus) e piapara (Leporinus elongatus e L. obtusidens), após 6 e $18 \mathrm{~h}$ de resfriamento foram de: 65 e 54 segundos para $P$. lineatus, 49 e 0 para L. elongatus, 155 e 76 segundos para L. obtusidens, respectivamente, diferem da média encontrada neste estudo, estes dados de duração da motilidade são de grande importância na prática, pois visam a programação nos trabalhos de fertilização in vitro para esta espécie.

Os resultados da percentagem de espermatozóides vivos são mostrados na Tabela 3 .

A interação das temperaturas de descongelamento com os diluidores apresentou efeitos diferentes $(\mathrm{P}<0,05)$, mostrando melhores resultados quando associado à temperatura de descongelamento a $50^{\circ} \mathrm{C}$ durante 10 segundos com o diluidor D1 (Glicose 5\%).

Tabela 2 - Duração da motilidade espermática observada no sêmen de piracanjuba pós-descongelamento

Table 2 - Duration of sperm motility of piracanjuba after thawing

\begin{tabular}{lcc}
\hline $\begin{array}{l}\text { Descongelamentos } \\
\text { Thawing rates }\end{array}$ & \multicolumn{2}{c}{$\begin{array}{c}\text { Duração da motilidade } \\
\text { espermática (s) }\end{array}$} \\
\cline { 2 - 3 } & $\begin{array}{c}\text { Duration of sperm motility }(s) \\
\text { Glicose 5\%(D1) }\end{array}$ & $\begin{array}{c}\text { Água de côco (D2) } \\
\text { Coconut water (D2) }\end{array}$ \\
\hline $\left.50^{\circ} \mathrm{C} / 10 \mathrm{~s} 1\right)$ & $153,33 \pm 48,02 \mathrm{a}$ & $136,33 \pm 42,72 \mathrm{a}$ \\
$60^{\circ} \mathrm{C} / 5 \mathrm{~s}$ & $135,67 \pm 47,20 \mathrm{a}$ & $188,00 \pm 88,45 \mathrm{a}$ \\
\hline
\end{tabular}

Não significativo em nível de $5 \%$ de probabilidade.

Not significant at $5 \%$ probability level.
Tabela 3 - Porcentagem de espermatozóides vivos observada no sêmen de piracanjuba pós-congelamento

Table 3 - Percentage of living sperms of piracanjuba after freezing

Descongelamento Porcentagem de espermatozóides

Thawing rates vivos

Porcentage of living sperm

\begin{tabular}{lcc}
\cline { 2 - 3 } & $\begin{array}{l}\text { Glicose 5\%(D1) } \\
\text { Glucose 5\% (D1) }\end{array}$ & $\begin{array}{c}\text { Água de côco (D2) } \\
\text { Coconut water (D2) }\end{array}$ \\
\hline $50^{\circ} \mathrm{C} / 10 \mathrm{~s}$ & $67,83 \pm 17,67 \mathrm{a}$ & $43,50 \pm 11,83 \mathrm{a}$ \\
$60^{\circ} \mathrm{C} / 5 \mathrm{~s}$ & $45,83 \pm 12,64 \mathrm{~b}$ & $48,00 \pm 16,11 \mathrm{a}$ \\
\hline
\end{tabular}

Médias seguidas da mesma letra na mesma coluna não apresentam diferenças significativas pelo teste Tukey, em nível de 5\%. Means in the same column followed by the same letter show no significant differences by Tukey test at 5\% probability level.

Houve também significância para o desdobramento do diluidor dentro de cada nível de descongelamento $(\mathrm{P}<0,01)$ para a percentagem de vivos indicando a temperatura de descongelamento a $50^{\circ} \mathrm{C}$ durante 10 segundos com melhores resultados quando utilizado juntamente com o diluidor D1.

Considerável progresso tem sido obtido recentemente no desenvolvimento de técnicas para a preservação de sêmen de peixes, sendo o processo criobiológico averiguado como mais eficiente (Stoss $\&$ Donaldson, 1982). A preservação desses gametas pode apresentar um papel importante, sobretudo favorecendo a instalação de programas genéticos e possibilitando a formação de bancos genéticos de espécies ameaçadas (Harvey, 1982).

\section{Conclusões}

O sêmen da piracanjuba (B. orbignyanus) após descongelamento apresentou motilidade espermática e duração da motilidade espermática compatível com a prática de fertilização in vitro quando utilizados descongelamentos a $50^{\circ} \mathrm{C}$ durante 10 segundos e diluidor com glicose $5 \%$ para a criopreservação do sêmen. Outros trabalhos deverão ser realizados a fim de verificar a taxa de fertilidade do sêmen, um parâmetro importante para avaliação de processos de criopreservação.

\section{Literatura Citada}

BANCO GENÉTICO INTERNACIONAL DE PESQUERIAS. Conservación genética de peces: manual de entrenamiento. Vitoria, BC, Canadá: International Fisheries Gene Bank, 1990. 36p. 
BEDORE, A.G. Características e criopreservação do sêmen de Pacuaranha, Piracatus mesopotamicus e de Piracanjuba, Brycon orbignyanus. Belo Horizonte: Universidade Federal de Minas Gerais, 1999. 53p. Dissertação (Mestrado em Biologia Celular) - Universidade Federal de Minas Gerais, 1999.

CAStagnolli, N. Criação de peixes de água doce. Jaboticabal: Universidade Estadual Paulista, 1992. 189p.

CONTE, L.; BOZANO, G.L.N.; FERRAZ DE LIMA, J.A. Influência do sistema de alimentação no crescimento da piracanjuba, Brycon orbignyanus, em gaiolas. Boletim Técnico do CEPTA, v.8, p.49-59, 1995.

DROKIN, H.S.; BARTSCHERER, H. Effect of cryopreservation on the fine structure of spermatozoa of Rainbow Trout (Oncorhynchus mykiss) and Brown Trout (Salmo trutta F. fario). Criobiology, v.37, p.263-70, 1998.

FERREIRA, D.F. Sistema de análise de variância (SISVAR). Lavras: Universidade Federal de Lavras, 1999. ver 4.3 (Build 43).

FRANCISCATTO, R.T.; MURGAS, L.D.S.; SILVA, M.O.B. Características seminais e taxa de fertilidade em piaparas (Leporinus obtsidens). In: CONGRESSO DE INICIAÇÃO CIENTÍFICA DA UNIVERSIDADE FEDERAL DE LAVRAS, 13., 2001, Lavras. Anais... Lavras: Universidade Federal de Lavras, 2001. p 297.

HARVEY, B. Preservation of fish gametes. In.: INTERNATIONAL SIMPOSIUM ON REPRODUCTIVE PHISIOLOGY OF FISH, Wageningen, 1982. Anais... Wageningen, 1982. 144p.

MELLO, C.B.M.; MURGAS, L.D.S.; SILVA, M.O.B. et al. Teste de fertilização de sêmen do pacu (Piracatus mesopotamicus), criopreservação com vários tipos de diluentes. In: SIMPÓSIO BRASILEIRO DE AQUACULTURA, 10., 1998, Recife. Resumos... Recife: 1998. p. 270 .
MUTR, J.F.; ROBERTS, R.J. Recent advances in aquaculture IV. Cambridge: Blackwell Scientific Publications, 1993. 124p.

MURGAS, L.D.S.; GUALHANONE, A.; SILVA M.O.B. et al. Calidad seminal del pez piracanjuba (Brycon orbignyanus) post-descongelación. Anales de Veterinária de Murcia, Espanha, 1998. v.17, p.8-16.

SANTOS, E. Peixes de água doce. Belo Horizonte: Itatiaia, 1981. v.2, p.58-60.

SILVA, M.O.B.; MURGAS L.D.S.; MELLO, C.B.M. et al. Avaliação do sêmen de "Curimba" (Pochilodus lineatus) e "Piaparas" (Leporinus obtusidens e Leporinus elongatus) após 6,18 e 24 horas de resfriamento à tempratura de $4^{\circ} \mathrm{C}$. In: SIMPÓSIO BRASILEIRO DE AQUACULTURA, 10., 1998, Recife. Resumos... Recife: 1998. p.294.

SILVA, M.O.B.; MELLO, C.B.M.; MURGAS, L.D.S. et al. Fertilização com sêmen congelado de pacu (Piracatus mesopotamicus). In: SIMPÓSIO BRASILEIRO DE AQUACULTURA, 10., 1998, Recife. Resumos... Recife: 1998. p. 275.

STOSS, J.; DONALDSON, E.M. Preservation of fish gametes. In: INTERNATIONAL SIMPOSIUM ON REPRODUCTIVE PHISIOLOGY OF FISH, 1982, Wageningen. Anais... Wageningen: 1982.p.114-22.

VASQUES, L.H. Histologia da piracanjuba, Brycon orbignyanus (Valenciennes, 1849) (Pisces, Characidadae): tecidos fundamentais. Jaboticabal: Universidade Estadual Paulista, 1997. 79p. Dissertação (Mestrado) - Universidade Estadual Paulista, 1997.

Recebido em: 12/11/01 Aceito em: 04/09/02 